\title{
Stage I Skin Cancer
}

National Cancer Institute

\section{Source}

National Cancer Institute. Stage I Skin Cancer. NCI Thesaurus. Code C5581.

Stage I includes: T1, N0, M0. T1: Tumor $2 \mathrm{~cm}$ or less in greatest dimension with less than two high-risk features. High-risk features for the primary tumor stag ing are defined as follows: depth/invasion of more than $2 \mathrm{~mm}$ thickness, Clark level equal or greater than IV, and perineural invasion. Anatomic location: primary site ear and primary site non-hairbearing lip. Differentiation: poorly differentiated or undifferentiated. N0: No regional lymph node metastasis. M0: No clinical or radiographic evidence of distant metastasis. (AJCC 7th ed.) 